Swarthmore College

Works

1994

\title{
Gender And The Meaning Of Difference: Postmodernism And Psychology
}

Rachel T. Hare-Mustin , '49

Jeanne Marecek

Swarthmore College, jmarece1@swarthmore.edu

Follow this and additional works at: https://works.swarthmore.edu/fac-psychology

Part of the Psychology Commons

Let us know how access to these works benefits you

\section{Recommended Citation}

Rachel T. Hare-Mustin , '49 and Jeanne Marecek. (1994). 1st. "Gender And The Meaning Of Difference: Postmodernism And Psychology". Theorizing Feminism: Parallel Trends In The Humanities And Social Sciences. 49-76.

https://works.swarthmore.edu/fac-psychology/1035

This work is brought to you for free by Swarthmore College Libraries' Works. It has been accepted for inclusion in Psychology Faculty Works by an authorized administrator of Works. For more information, please contact myworks@swarthmore.edu. 


\title{
The Mutual Influence of the
}

Humanities and Social Sciences

\section{Gender and the Meaning of Difference: Postmodernism and Psychology}

\author{
RaChel T. Hare-Mustin \& \\ Jeanne MareceK
}

C Onventional meanings of gender typically focus on difference, emphasizing how women differ from men. These differences have furnished support for the norm of male superiority. Until recently, psychological inquiry into gender has held to the construction of gender as difference. Thus, psychologists have focused on documenting differences between men and women, and their findings have served as scientific justification for male-female inequality (Lott, 1985; Morawski, 1985; Shields, 1975; Weisstein, 1971). When we examine theories of psychotherapy, we find that they, too, have supported the cultural meanings of gender (Hare-Mustin, 1983).

One recent line of inquiry by feminist psychologists has involved reexamining gender with the goal of deemphasizing difference by sorting out genuine male-female differences from stereotypes. Some examples include Janet Hyde's (1981) meta-analyses of cognitive differences, Eleanor Maccoby and Carolyn Jacklin's (1975) review of sex differences, and Jacquelynne Eccles's work on math achievement (Eccles, 1989; Eccles \& Jacobs, 1986). The results of this work dispute the contention that many male-female differences are universal, dramatic, or enduring (Deaux, 1984; Unger, 1979; Wallston, 1981). Moreover, this line of inquiry sees the origins of difference as largely social and cultural rather than biological. Thus, most differences between males and females are seen as culturally specific and historically fluid.

Another line of inquiry, exemplified in recent feminist psychodynamic theories (e.g., Chodorow, 1978; Eichenbaum \& Orbach, 1983; Miller, 1986), takes as its goal the reaffirmation of gender differences. Although these theories provide varying accounts of the origins of difference, they all emphasize deep-seated and enduring differences between women and men in what is referred to as core self-structure, identity, and relational capacities. Other theorists have extended this work to suggest that these gender differences in psychic structure give rise to cognitive 
differences, such as differences in moral reasoning and in acquiring and organizing knowledge (cf. Belenky, Clinchy, Goldberger \& Tarule, 1986; Gilligan, 1982; Keller, 1985). These theories represent differences between men and women as essential, universal (at least within contemporary Western culture), highly dichotomized, and enduring.

These two lines of inquiry have led to two widely held but incompatible representations of gender: one that sees considerable similarity between males and females, and another that sees profound differences. Both groups of theorists have offered empirical evidence, primarily quantitative in the first case and qualitative in the second. We believe that it is unlikely that further empirical evidence will resolve the question of whether men and women are similar or different. The two lines of inquiry described here emerge from different intellectual traditions, construe their domains of study differently, and rely on such different methods that consensus on a given set of conclusions seems unlikely. Moreover, even if consensus were possible, the question of what constitutes differentness would remain.

What constitutes differentness is a vexing question for psychologists who study sex and gender. Research that focuses on average differences between men and women may produce one conclusion while research that focuses on the full range of variations and the overlap (or lack of overlap) at the extremes of the range may produce another (Luria, 1986). An illustration can make this clearer: Although on average, American men are several inches taller than American women, we can readily think of some men who are shorter than many or even most women. The size and direction of gender differences in social behaviors, such as aggression or helping, often vary according to the norms and expectations for men and women that are made salient by the setting in which the behavior takes place (Eagly \& Crowley, 1986; Eagly \& Steffen, 1986). Studies in experimental laboratories can produce different results from field observations in real settings. Even more troubling, the very criteria for deciding what should constitute a difference as opposed to a similarity are disputed. How much difference makes a difference? Even the anatomical differences between men and women seem trivial when humans are compared to daffodils or ducks.

What are we to make of the difference versus no difference debate? Rather than debating which of these representations of gender is "true," we shift to the metaperspective provided by postmodernism. From this perspective, we can entertain new and possibly more fruitful questions about representations of gender, including the political and social functions that the difference and no difference positions serve. This perspective opens the way to alternative representations of gender that would raise new questions or recast old ones for psychologists.

\section{Postmodernism and Meaning}

Two recent intellectual movements, constructivism and deconstruction, challenge the idea of a single meaning of reality and a single truth. Rather than concerning themselves with a search for "the truth," they inquire instead about the way meanings are negotiated, the control over meanings by those in authority, and 
how meanings are represented in language. The current interest in constructivism and deconstruction reflects the growing skepticism about the positivist tradition in science and essentialist theories of truth and meaning (Rorty, 1979). Both constructivism and deconstruction challenge these positions, asserting that the social context shapes knowledge, and that meanings are historically situated and constructed and reconstructed through the medium of language.

The connection between meaning and power has been a focus of postmodernist thinkers (Foucault, 1973; Jameson, 1981). Their inquiry into meaning focuses especially on language as the medium of cognitive life and communication. Language is seen not simply as a mirror of reality or a neutral tool (Taggart, 1985; Wittgenstein, 1960; 1967). As Bruner (1986) points out, language "imposes a point of view not only about the world to which it refers but toward the use of the mind in respect to this world" (121). Language highlights certain features of the objects it represents, certain meanings of the situations it describes. "The word-no matter how experimental or tentative or metaphoric-tends to replace the things being described" (Spence, 1987, 3). Once designations in language become accepted, one is constrained by them not only in communicating ideas to others, but in the generation of ideas as well (Bloom, 1981). Language inevitably structures one's own experience of reality as well as the experience of those to whom one communicates. Just as in any interaction we cannot "not communicate," so at some level we are always influencing one another and ourselves through language.

Meaning-making and control over language are important resources held by those in power. Like other valuable resources, they are not distributed equitably across the social hierarchy. Indeed, Barthes (1972) has called language a sign system used by the powerful to label, define, and rank. Language is never innocent. Throughout history, dominant groups have asserted their authority over language. Our purpose here is to draw attention to the fact that men's influence over language is greater than that of women; we do not argue that women have had no influence over language. Within most social groups, males have had privileged access to education and thus have had higher rates of literacy than females; this remains true in many developing countries today (Newland, 1979). Men's dominance in academic institutions influences the social production of knowledge, including the concepts and terms in which people think about the world (Andersen, 1983). In addition, more men are published and men control the print and electronic media (Strainchamps, 1974). The arbiters of language usage are primarily men, from Samuel Johnson and Noah Webster to H. L. Mencken and Strunk and White.

When meaning-making through language is concentrated among certain groups in society, the meanings put forth can only be partial, because they exclude the experiences of other social groups. Yet the dominant group's influence over meaning-making is such that partial meanings are represented as if they were complete. In the instance of male control over language, the use of the generic masculine is a ready example of representing a partial object, the masculine, as complete, that is, as encompassing both male and female. Although not all men 
have influence over language, for those who do, such authority confers the power to create the world from their point of view, in the image of their desires.

In this chapter, we try to rethink the psychology of gender from the vantage point of constructivism and deconstruction. We first take up constructivism. We examine various constructions of gender and identify the problems associated with the predominant meaning of gender, that of male-female difference. We then turn to deconstruction. We show how a deconstructive approach can reveal alternative meanings associated with gender. In therapy, deconstruction can be a means of disrupting clients' understanding of reality by revealing alternative meanings. New meanings offer new possibilities for action and thus can foster change. We do not provide an exhaustive review of sex differences in psychology or propose a new theory of gender. Rather, we shift the discussion to a metatheoretical level in order to consider gender theorizing. Our purpose is not to answer the question of what is the meaning of gender but to examine where the question has taken us thus far and then to move on to new areas of inquiry.

\section{The Construction of Reality}

Constructivism asserts that we do not discover reality, we invent it (Watzlawick, 1984). Our experience does not directly reflect what is out there but is a selecting, ordering, and organizing of it. Knowing is a search for "fitting" ways of behaving and thinking (Von Glaserfeld, 1984). Rather than passively observing reality, we actively construct the meanings that frame and organize our perceptions and experience. Thus, our understanding of reality is a representation, not an exact replica, of what is out there. Representations of reality are shared meanings that derive from shared language, history, and culture. Rorty (1979) suggests that the notion of accurate representation is a compliment we pay to those beliefs that are successful in helping us do what we want to do. The "realities" of social life are products of language and agreed-on meanings.

Constructivism challenges the scientific tradition of positivism, which holds that reality is fixed and can be observed directly, uninfluenced by the observer (Gergen, 1985; Sampson, 1985; Segal, 1986). As Heisenberg (1952) has pointed out, a truly objective world, devoid of all subjectivity, would have no one to observe it. Constructivism also challenges the presumption of positivist science that it is possible to distinguish facts from values. For constructivists, values and attitudes determine what are taken to be facts (Howard, 1985). It is not that formal laws and theories in psychology are wrong or useless; rather, as Kuhn (1962) asserted, they are explanations based on a set of agreed-on social conventions. Whereas positivism asks what are the facts, constructivism asks what are the assumptions; whereas positivism asks what are the answers, constructivism asks what are the questions.

The positivist tradition holds that science is the exemplar of the right use of reason, neutral in its methods, socially beneficial in its results (Flax, 1987). Historically, the scientific movement challenged the canons of traditional belief and the authority of church and state. Science was a reform movement that struggled to 
supplant faith as the sole source of knowledge by insisting on the unity of experience and knowing. For Western society today, science has largely displaced church and state authority so that scientific has itself become a euphemism for proper.

Constructivism holds that scientific knowledge, like all other knowledge, cannot be disinterested or politically neutral. In psychology, constructivism, drawing on the ideas of Bateson and Maturana, has influenced epistemological developments in systems theories of the family (Dell, 1985). Constructivist views have also been put forth in developmental psychology (Bronfenbrenner, Kessel, Kessen \& White, 1986; Scarr, 1985), in the psychology of women (Unger, 1983, and this book), and in the study of human sexuality (Tiefer, 1987). Constructivist views also form the basis of the social constructionism movement in social psychology, which draws inspiration from symbolic anthropology, ethnomethodology, and related movements in sociology and anthropology (Gergen, 1985; Kessler \& McKenna, 1978).

From a constructivist perspective, theories of gender, like all scientific theories, are representations of reality that are organized within particular assumptive frameworks and that reflect certain interests. Below, we examine gender theorizing in psychology and indicate some of the assumptions and issues that a constructivist approach makes apparent.

\section{The Construction of Gender as Difference}

From a constructivist standpoint, the real nature of male and female cannot be determined. Constructivism focuses our attention on representations of gender rather than on gender itself. We note first that most languages, including our own, are elaborately gendered. Gender differentiation is a preeminent phenomenon of symbolic life and communication in our society, although this is not the case in all languages and cultures. Nonetheless, the English language still lacks adequate terms for speaking of each gender. Male-female has the advantage of referring to individuals across the entire life span, but the terms imply biological characteristics and fail to distinguish humans from other species. Men-women is more restrictive, referring specifically to humans, but it has the disadvantage of omitting childhood and adolescence. In this chapter, we use men and women for the most part, but we use male and female when we wish to include individuals at any point in the life span.

The very term gender illustrates the power of linguistic categories to determine what we know of the world. The use of gender in contexts other than discussions of grammar is quite recent. Gender was appropriated by contemporary American feminists to refer to the social quality of distinctions between the sexes (Scott, 1985). Gender is used in contrast to terms like sex and sexual difference for the explicit purpose of creating a space in which socially mediated differences between men and women can be explored apart from biological differences (Unger, 1979). The germinal insight of feminist thought was the discovery that woman is a social category. So although sexual differences can be reduced to the reproductive system in males (sperm production) and females (ovulation, pregnancy, childbirth, 
and lactation), sex differences do not account for gender, for women's social, political, and economic subordination or women's child care responsibilities.

From the vantage point of constructivism, theories of gender are representations based on conventional distinctions. In our view, such theories embody one of two contrasting biases, alpha bias and beta bias (Hare-Mustin, 1987). Alpha bias is the tendency to exaggerate differences; beta bias is the tendency to minimize or ignore differences.

The alpha-beta schema is in some ways analogous to that in scientific hypothesis testing in experimental psychology and thus is a schema familiar to psychologists. In hypothesis testing, alpha or Type 1 error involves reporting a significant difference when one does not exist; beta or Type 2 error involves overlooking a significant difference when one does exist. In our formulation, the term bias refers not to the probability of error (which would imply that there is a correct position), but to a systematic slant or inclination to emphasize certain aspects of experience and overlook other aspects. This inclination or tendency is presumably related to the standpoint of the knower, that is, the position where he or she is located within and as part of the context. Thus, the standpoint of the knower necessarily shapes her or his view of reality. Far from deterring the knower from gaining knowledge, taking a standpoint can be a positive strategy for generating new knowledge (Hartsock, 1985). Our use of the term bias underscores our contention that all ideas about difference are social constructs; none can be mirrors of reality. Alpha and beta bias can be seen in representations of gender, race, class, age, and the like that either emphasize or overlook difference. Here we use the alpha-beta schema to examine recent efforts to theorize gender.

\section{Alpha Bias}

Alpha bias is the exaggeration of differences. The view of male and female as different and opposite and thus as having mutually exclusive qualities transcends Western culture and has deep historical roots. Ideas of male-female opposition are present in Eastern thought and throughout Western philosophy, including the writings of Aristotle, Aquinas, Bacon, and Descartes, as well as the writings of liberal theorists such as Locke and romanticists such as Rousseau (Grimshaw, 1986). Throughout Western history, woman has been regarded as the repository of nonmasculine traits, an "otherness" men assign to women.

The scientific model developed by Francis Bacon was based on the distinction between "male" reason and its "female" opposites-passion, lust, and emotion (Keller, 1985). Because women were restricted to the private sphere, they did not have access to the knowledge available in the public realm. The knowledge women did have, such as witchcraft, was disparaged or repudiated. As Evelyn Fox Keller points out, women's knowledge was associated with insatiable lust; men's knowledge was assumed to be chaste. In Bacon's model of science, nature was cast in the image of the female, to be subdued, subjected to the penetrating male gaze, and forced to yield up her secrets (cf. Keller, 1985; Merchant, 1980). Bacon's views 
are but one manifestation of the long-standing association of women with nature and emotion and men with reason, technology, and civilization (Ortner, 1974). The material body has been a symbol of human limitation and decay since at least early Christian times. Hence, men sought to be other than their bodies, to transcend their bodies. They dissociated themselves from their bodies and associated women with materiality, the sphere of nature, and the body (Butler, 1987). The opposition of reason and emotion, as well as the opposition of civilization and nature, emphasized in the Enlightenment, served in later times to reinforce liberalism's emphasis on rationality as the capacity that distinguishes humans from animals (Grimshaw, 1986).

In psychology, alpha bias can be readily seen in most psychodynamic theories. Freudian theory is not neutral about sexual differences but imposes meanings. It takes masculinity and male anatomy as the human standard; femininity and female anatomy are deviations from that standard. Thus, Freud characterized women's bodies as not having a penis rather than as having the female external genitalia. Similarly, he portrayed feminine character in terms of its deficiencies relative to masculine character. The Jungian idea of the animus and the anima also places the masculine and the feminine in opposition.

More recent psychodynamic theories also depict women as sharply divergent from men. For example, Erikson (1964) wrote that female identity is predicated on "inner space," a somatic design that "harbors ... a biological, psychological, and ethical commitment to take care of human infancy ..." (586), and a sensitive indwelling. Male identity is associated with "outer space," which involves intrusiveness, excitement, and mobility, leading to achievement, political domination, and adventure seeking. In Lacan's (1985) poststructuralist view, women are "outside" language, public discourse, culture, and the law. For Lacan, the female is defined not by what is, but by the absence or lack of the phallus as the prime signifier. In these ways psychodynamic theories overlook similarities between males and females and instead emphasize differences.

Parsons's sex-role theory, which dominated the social theories of the 1950 and 1960 , also emphasizes male-female differences (Parsons \& Bales, 1955). The very language of sex-role theory powerfully conveys the sense that men's and women's roles are fixed and dichotomous, as well as separate and reciprocal (Thorne, 1982). Parsons asserted that men were instrumental and women were expressive, that is, men were task-oriented and women were oriented toward feelings and relationships. Parsons's sex-role theory was hailed as providing a scientific basis for relegating men and women to separate spheres. Men's nature suited them for paid work and public life; women's nature suited them for family work and home life. Thus women became first in "goodness" by putting their own needs secondary to those of their families and altruistically donating their services to others (Lipman-Blumen, 1984). Parsons believed that separate spheres for men and women were functional in reducing competition and conflict in the family and thus preserving harmony. The role definitions that Parsons put forward came to 
serve as criteria for distinguishing normal individuals and families from those who were pathological or even pathogenic (cf. Broverman, Broverman, Clarkson, Rosenkrantz \& Vogel, 1970). The criteria associated with sex-role differentiation continue to be applied to family structure and functioning in such theories as contemporary exchange theory (Nye, 1982) and structural family therapy (Minuchin, 1974).

Alpha bias, or the inclination to emphasize differences, can also be seen in feminist psychodynamic theories (cf. Chodorow, 1978; Eichenbaum \& Orbach, 1983; Gilligan, 1982; Miller, 1986). According to Nancy Chodorow (1978), boys and girls undergo contrasting experiences of identity formation during their early years under the social arrangement in which the care of infants is provided exclusively by women. Her influential work, which is based on object-relations theory, argues that girls' early experiences involve similarity and attachment to their mothers while boys' early experiences emphasize difference, separateness, and independence. These experiences are thought to result in broad-ranging gender differences in identity, personality structure, and psychic needs in adulthood. Women develop a deep-seated motivation to have children, whereas men develop the capacity to participate in the alienating work structures of advanced capitalism. Thus, according to Chodorow, the social structure produces gendered personalities that reproduce the social structure. Although Chodorow locates the psychodynamics of personality development temporally and situationally in Western industrial capitalism, psychologists who draw on her work often overlook this point concerning the social context. Her work is used to assert that there are essential differences between women and men and to view these, rather than the social structure, as the basis for gender roles (cf. Chernin, 1986; Eichenbaum \& Orbach, 1983; Schlachet, 1984; Jordan \& Surrey, 1986). In any case, both Chodorow's theory and the work of her followers emphasize gender difference and thus exemplify alpha bias.

In her approach to women's development, Carol Gilligan (1982) harks back to Parsons's duality, viewing women as relational and men as instrumental and rational. Her theory of women's moral development echoes some of the gender differences asserted by Freud (1964) and Erikson (1964). She describes female identity as rooted in connections to others and relationships. She views female morality as based on an ethic of care and responsibility rather than fairness and rights. Unlike Freud, however, she views women's differences from men in a positive light.

Both traditional psychodynamic theories and the recently developed feminist psychodynamic theories emphasize differences between men and women while overlooking the similarities between them. Whereas the emphasis on difference in traditional theories went hand in hand with a devaluation of what was seen as female, feminists' emphasis on difference is coupled with a positive evaluation of women's attributes. Their emphasis on women's unique capacities for relationships and on the richness of women's inner experience has been an important resource for the movement within feminism known as cultural feminism. Cultural 
feminism encourages the development and expression of a women's culture, celebrates the special qualities of women, and values relationships among women.

\section{Beta Bias}

The inclination to ignore or minimize differences, beta bias, has been less prominent in psychological theory than alpha bias, and thus our treatment of it is necessarily briefer. One example of beta bias in theory development is the practice, common until recent decades, of drawing generalizations about human behavior, adult development, and personality from observations limited to males (Wallston, 1981). Male experience was assumed to represent all experience. This is an instance of beta bias insofar as generalizations about human experience based only on the male life course assume that women's experiences are no different than men's. Such generalizations offer only a partial view of humanity.

Another common instance of beta bias is the tendency to overlook both the differences in the social and economic resources that men and women typically have at their disposal as well as the differences in the social meanings and consequences of their actions. Thus, beta bias can be seen in social policies that provide equivalent benefits for men and women but overlook their disparate needs (Weitzman, 1985). Two examples, which we take up later, are comparable parental leave and no-fault divorce. Beta bias can also be seen in educational and therapeutic programs that focus on transforming the individual while leaving the social context unchanged. For example, some programs purport to groom women for personal or professional success by providing training in what are deemed male behaviors or skills, such as assertiveness, authoritative speech patterns, or certain managerial styles. Thus, if a woman wants to succeed as a manager, she is instructed to copy the demeanor and actions of successful men. Such programs presume that a certain manner of speaking or acting will elicit the same reaction from others regardless of the sex of the actor. This can be questioned (Gervasio \& Crawford, 1989; Marecek \& Hare-Mustin, 1987); for example, asking for a date, a classic task in assertiveness training, is judged differently for a woman than a man (Muehlenhard, 1983).

Beta bias can also be seen in theories of gender that represent masculine and feminine roles of traits as counterparts, as the construct of psychological androgyny does. The idea of masculinity and femininity as counterparts implies their symmetry and equivalence and thus obscures gender differences in power and social value. Sandra Bem's (1976) theory of psychological androgyny, which called for the creation of more balanced and healthy individuals by integrating positive masculine and feminine qualities, implies the equivalence of such qualities (Morawski, 1985; Worell, 1978).

Bem's original hypotheses suggested that individuals who identified themselves as highly feminine and those who identified themselves as highly masculine would be equally handicapped in performing "cross-sex" tasks and equally disadvantaged in terms of psychological well-being. But attempts to demonstrate this empirically did not yield such symmetrical effects (Morawski, 1987); rather, a masculine sex-role orientation tended to be associated with greater adaptiveness, 
as well as higher scores on indices of self-esteem and other aspects of psychological well-being. This is perhaps not surprising: If society values masculine qualities more highly than feminine qualities, individuals who have (or perceive themselves to have) those qualities should feel better about themselves. This is not to say that every quality associated with masculinity is regarded as positive. Aggression, for instance, is deplored outside of combat situations and competitive sports.

Beta bias can also be seen in theories of family functioning that ignore gender. In all societies, four primary axes along which hierarchies are established are class, race, gender, and age. Within families, class and race usually are constant, but gender and age vary. Family systems theories, however, disregard gender and view generation (that is, age) as the central organizing principle in the family (Hare-Mustin, 1987). Such theories emphasize the importance of the boundaries that define the differences in power and responsibility between the parental generation and the children. In so doing, they deflect attention from questions about the distribution of power and resources within generations of a family. Are mothers as powerful as fathers? Are daughters afforded the same resources and degree of autonomy as sons? By regarding all members of a generation as equal interacting participants in the family system, systems theories put forward a neutered representation of family life (Libow, 1985).

\section{The Question of Utility}

Rather than debate the correctness of various representations of gender, the "true" nature of which cannot be known, constructivism turns to the utility or consequences of these representations. How, we ask, do representations of gender provide the meanings and symbols that organize scientific and therapeutic practice in psychology? What are the consequences of representing gender in ways that either emphasize or minimize male-female differences? We use the alphabeta schema as a framework for discussing the utility of gender theories.

\section{The Utility of Alpha Bias}

Because alpha bias has been the prevailing representation of gender we take up the question of its utility first. Alpha bias has had a number of effects on our understanding of gender. An important positive consequence of alpha bias, or focusing on differences between women and men, is that it has allowed some theorists to assert the worth of certain so-called feminine qualities. This assertion has the positive effect of countering the cultural devaluation of women and encouraging greater self-acceptance among women (Echols, 1983). Further, the focus on women's special qualities by some feminists has also prompted a critique of those cultural values that excuse or even encourage aggression, extol the pursuit of self-interest, and foster narrow individualism. It has furnished an impetus for the development of a feminist social ethics and for a variety of related philosophical endeavors (Eisenstein, 1983). The emphasis on women's differences from men fosters a corresponding appreciation of the commonalities women share, an appreci- 
ation that can help to generate positive emotional bonds among women. Sisterhood and solidarity have spurred collective action by women to gain recognition and power.

Unfortunately, exaggerating gender difference does not always support the aims of feminism. By construing women as different and devaluing them, alpha bias fosters solidarity between men by construing women as a deviant out-group, which can then be devalued. In Durkheim's terms, deviance supports in-group solidarity. Defining a sharp boundary between male and female supports the status quo by exacerbating male fears of being viewed as feminine. This serves to enforce conformity by males to masculine stereotypes. Moreover, exaggerating women's difference from men fosters the view of woman as the Other (Beauvoir, 1953). Further, this distancing and alienating view of women by the dominant male culture opens the way to treating women as objects, as is apparent in certain pornographic images and in much of the physical and sexual abuse of females.

Alpha bias also supports the status quo by denying that change is needed in the structure of work and family life (Gilder, 1987; Marshner, 1982). So, for example, traditionalists assert that women are not as intellectually capable as men, women are temperamentally better suited for care-taking roles and, as was argued in the Sears sex discrimination case, women prefer not to undertake stereotyped male roles (Erikson, 1964; Rosenberg, 1986; Rossi, 1984). Women's presumed differences from men are used to justify unequal treatment. Yet, as Patricia Mills (1987) suggests, it is women's confinement to the family that secures her difference. The possibility that it is the unequal treatment that might lead to the apparent differences between men and women is hidden from view.

The idea that male and female are opposites masks inequality between men and women as well as conflict between them. By construing rationality as an essential male quality and relatedness as an essential female quality, for example, such theories as those of Gilligan and Parsons conceal the possibility that those qualities result from social inequities and power differences. Men's propensity to reason from principles might stem from the fact that the principles were formulated to promote their interests; women's concern with relationships can be understood as a need to please others that arises from lack of power (Hare-Mustin \& Marecek, 1986). Typically, those in power advocate rules, discipline, control, and rationality, while those without power espouse relatedness and compassion. Thus, in husband-wife conflicts, husbands call on rules and logic, whereas wives call on caring. But, when women are in the dominant position, as in parent-child conflicts, they emphasize rules while their children appeal for sympathy and understanding or for exceptions based on special circumstances. This suggests that rationality and relatedness are not gender-linked traits, but rather stances evoked by one's position in a social hierarchy.

Others have offered related accounts of how women's greater concern with relationships might be a consequence of women's position in the social hierarchy rather than an essential female attribute. Wilden (1972), for example, proposes that low social status imparts a need to monitor where one stands in a relationship: "Anyone in a social relationship which defines him or her as inferior must 
necessarily be much more concerned to discover what the relationship is about than to communicate or receive any particular message within it" (297).

Women's caring is but one example of a behavior that has been represented as a gender difference but can be more adequately represented as a way of negotiating from a position of low power. As Bernice Lott discusses below, many other differences between men and women are best construed as stances associated with their relative positions in the social hierarchy rather than as differences of gender per se. These alternative accounts open the way for psychologists to consider why every woman is not concerned with caring and relationships and why some men are.

Feminist psychodynamic theories make assertions of extensive male-female personality differences throughout life. Even when these theories applaud the personality attributes of women, they can serve as justification for restricting individuals to a particular social place. Further, critics have challenged the idea that a brief period in infancy could be responsible for creating the broad-ranging differences that psychodynamic theorists assert and overriding subsequent experiences in human development. Critics similarly challenge whether personality differences alone could be responsible for the gendering of all social institutions throughout history (cf. Kagan, 1984; Lott, 1987; Scott, 1985); that is, feminist psychodynamic theories have been criticized for overplaying the influence of early experience and individual personality to the neglect of economic conditions, social role conditioning, and historical change.

A further question has been raised as to whether changes in patterns of infant care-giving such as Nancy Chodorow (1978) and Dorothy Dinnerstein (1976) propose are sufficient to undermine gender difference and thereby to effect social transformation. There is an uncomfortable literalism in imputing such power to such a small segment of experience. Joan Scott (1985) has drawn attention to this problem in terms of representing the well-ordered family as the foundation of a well-ordered society.

In focusing on the question of why differences exist, feminist psychodynamic theories disregard the question of why domination exists. Iris Young (1983) points out that psychodynamic theories posit a masculine desire for power but fail to account for how men achieve power. The identification of a problem does not constitute an explanation.

Alpha bias, the exaggerating of differences between groups, has the additional consequence of ignoring or minimizing the extent of differences (or variability) among members of each group. The focus on Woman obliterates the sight of women. Further, such outgroups as women are viewed as more homogeneous than dominant groups (Park \& Rothbart, 1982). Differences among men are readily identified, but all women are regarded as pretty much the same. Thus, men are viewed as individuals, but women are viewed as women. As a result, most psychological theories of gender have been slow to concern themselves with differences among women that are due to race, ethnicity, class, age, marital status, and a variety of social circumstances. 
Another consequence of alpha bias is the tendency to view men and women not only as different but as opposite. The conception of masculine and feminine as embodying opposite and mutually exclusive traits is not only prevalent in the culture at large, but it has been embedded in certain well-established psychological tests. These include the Terman-Miles (1936) Masculinity-Femininity Personality Scale (M-F), the California Personality Inventory (Gough, 1964), and the Minnesota Multiphasic Personality Inventory (Hathaway \& McKinley, 1943). The existence of these scales testifies to fifty years of psychological effort to evaluate the constructs of masculinity and femininity, an unrelenting search for the presumed core of what defines masculine and feminine (Morawski, 1987). Anne Constantinople (1973) has questioned the usefulness of the M-F construct, pointing out the vague definitions used in test construction: $\mathrm{M-F}$ is defined as whatever masculinity-femininity tests measure. She concluded that such tests merely measured the differences in the responses of men and women.

These tests are constructed so that a respondent must disavow feminine qualities in order to be categorized as masculine and vice versa. Thus, masculinityfemininity is represented as a single bipolar dimension, a unitary continuum. Masculinity and femininity are defined in terms of one another; what one is, the other is not.

Such dichotomies caricature human experience; for example, to maintain the illusion of male autonomy, the contribution of women's work at home and in the workplace must be overlooked. Feminist social scientists have observed that women and the family have been asked to compensate for the indifference and hostility of the outer world. Thus, the home is viewed as a haven (Lasch, 1977), but it is actually that women are the haven for men. The home is a metaphor that serves to obscure men's dependence on women and thus perpetuates the illusion of male autonomy. Similarly, the corporate world is seen as the locus of men's achievement and independence, but this overlooks the contribution of women. The extent to which female support personnel, such as secretaries and receptionists, cover up their bosses' absences and shortcomings, administer their work day, and provide personal service is obscured. In both cases, women are expected to provide for men's physical needs and mediate their social relations.

The portrayal of women as relational also ignores the complexity of their experiences. Rearing children involves achievement, and nurturing others involves power over those in one's care (Hare-Mustin \& Marecek, 1986). When gender is represented as dichotomized traits, the extent to which presumed opposites include aspects of each other is overlooked. It is of interest to note that when women enter the "man's world" of business, they often flounder at first because they assume it operates according to formal rules and principles, they underestimate the importance of informal relationships, reciprocal favors, and personal influence.

Gender dichotomies regarding work and housework also caricature the actual experiences of both housewives and working women. In industrialized societies one's value is associated with the money one earns. Those who do not earn money-housewives, children, and old people-have an ambiguous status 
(Hare-Mustin, 1978). The contemporary focus on industrial production has led to the belief that households no longer produce anything important, and consequently that housewives no longer have much to do. But what exists is better represented as a two-tiered production system in which work for money is carried on outside the home while a familial production system continues within. As Ruth Schwartz Cowan (1983) has pointed out, women produce without payment meals, clean laundry, healthy children, well-fed adults, and transportation for goods and people at a level unknown in past times. Yet paid workers are seen as productive and housewives are not.

The view of male and female as opposite also supports the idea of separate spheres. The idea of separate spheres lives on, even though the majority of women are now in the paid labor force and operate in both spheres. A false symmetry embodied in the notion of separate spheres obscures women's dual roles and work overload (Hare-Mustin, 1988).

The representation of gender as dichotomies or opposites has had a long history in human thought. Even the autonomy-relatedness dichotomy was foreshadowed by earlier dichotomies such as agentic-communal (Bakan, 1966) and instrumental expressive (Parsons \& Bales, 1955). Indeed, man-woman may serve as a universal binary opposition. If so, this is not the result simply of a faulty definition, but as Wilden (1972) says, of prevailing ideology. The representation of gender as opposition has its source not in some accidental confusion of logical typing, but in the dominant group's interest in preserving the status quo. Calling the psychosocial and economic relations of men and women opposition imputes symmetry to a relationship that is unequal. As Dorothy Dinnerstein (1976) pointed out, women have been discontent with the double standard, but men on the whole are satisfied with it. Further, denying the interrelationships between male and female serves to maintain inequality.

Alpha bias, or exaggerating differences, thus plays an important role in preserving the status quo. Perhaps for this reason, the mass media often promulgate representations of gender that emphasize difference and underplay those that minimize difference. As Martha Mednick (1989) documents, the media have given extensive coverage to women's difference, such as their "fear of success," their lack of a "math gene," and their "different voice." Similarly, popular self-help books appeal to women's supposedly greater expressiveness, empathy, and sensitivity, while holding women responsible for all that goes wrong in intimate relationships (Worrell, 1988). Points of similarity between women and men do not make news, nor are refutations of exaggerated claims of male-female difference considered newsworthy.

\section{The Utility of Beta Bias}

Beta bias, or minimizing differences, also has consequences for understanding gender, but its consequences have received less attention. On the positive side, equal treatment under the law has enabled women to gain greater access to educational and occupational opportunities, as well as equal pay for equal work. This is 
largely responsible for the improvement in the status of some women over the last two decades (Dionne, 1989).

Arguing for no differences between women and men, however, draws attention away from women's special needs and from differences in power and resources between women and men. A ready example is seen in the statutes legislating equal pay for equal work, which have had relatively little effect on equalizing incomes across gender. This is because most women work in female-identified sectors of the economy in which wages are low. In a society in which one group holds most of the power, ostensibly neutral actions usually benefit members of that group. In Lenore Weitzman's (1985) research, for example, no-fault divorce settlements were found to have raised men's standard of living 42 percent while lowering that of women and children 73 percent. Another example is the effort to promote public policies granting comparable parental leave for mothers and fathers of newborns. Such policies overlook the physical effects of giving birth from which women need to recuperate and the demands of breastfeeding that are met uniquely by women who nurse their infants.

Giving birth is, paradoxically, both an ordinary event and an extraordinary one, as well as the only visible biological link in the kinship system. The failure of the workplace to accommodate women's special needs associated with childbirth represents beta bias, in which male needs and behaviors set the norm, and women's unique experiences are overlooked.

In therapy, treating men and women as if they were equal is not always equitable (Gilbert, 1980; Margolin, Talovic, Fernandez \& Onorato, 1983). In marital and family therapy, treating partners as equals can overlook structural inequalities within the relationship. Some family systems theorists have tried to dismiss the concept of power as an epistemological error, arguing that both partners in a relationship contribute to the maintenance of the relationship. The notion of reciprocity, however, implies that the participants are not only mutually involved but equally involved in maintaining the interaction, and that they can equally influence its outcome (MacKinnon \& Miller, 1987). As Virginia Goldner points out, this is not unlike the "kind of moral relativism in which the elegant truth that master and slave are psychologically interdependent drifts into the morally repugnant and absurd notion that the two are therefore equals" $(1987,111)$. As long as the social status and economic resources of the husband exceed those of the wife, marital contracts and quid pro quo bargaining strategies for resolving conflicts between partners will not lead to equitable results. Sex-fair or gender-neutral therapies that advocate nonpreferential and nondifferential treatment of women and men to achieve formal equality can inadvertently foster inequality (Bernal \& Ysern, 1986; Jacobson, 1983; Marecek \& Kravetz, 1977).

Our purpose in examining representations of gender has not been to catalogue every possible consequence of alpha and beta bias but to demonstrate that representation is never neutral. From the vantage point of constructivism, theories of gender can be seen as representations that construct our knowledge of men and women and inform social and scientific practice. Gender selects and gives meaning to sexual differences. Deconstruction provides another approach for examin- 
ing representation and meaning in language. We now turn to the ways in which deconstruction can be used to examine the meanings of gender in the practice of therapy.

\section{Deconstruction}

Just as constructivism denies that there is a single fixed reality, the approach to literary interpretation known as deconstruction denies that texts have a single fixed meaning. Deconstruction offers a means of examining the way language operates outside our everyday awareness to create meaning (Culler, 1982). Deconstruction is generally applied to literary texts, but it can be applied equally to scientific texts, or, as we suggest below, to therapeutic discourse.

A primary tenet of deconstruction is that texts can generate a variety of meanings in excess of what is intended. In this view, language is not a stable system of correspondences of words to objects but "a sprawling limitless web where there is constant circulation of elements" (Eagleton, 1983, 129). The meaning of a word depends on its relation to other words, specifically, its difference from other words.

Deconstruction is based on the philosophy of Derrida, who moves beyond the structuralist thesis that posits closed language systems. Derrida has pointed out that Western thought is built on a series of interrelated hierarchical oppositions, such as reason-emotion, presence-absence, fact-value, good-evil, male-female (Culler, 1982). In each pair, the terms take their meaning from their opposition to (or difference from) each other; each is defined in terms of what the other is not. The first member of each pair is considered "more valuable and a better guide to the truth" (Nehamas, 1987, 32). But Derrida challenges both the opposition and the hierarchy, drawing attention to how each term contains elements of the other and depends for its meaning on the other. It is only by marginalizing their similarities that their meaning as opposites is stabilized and the value of one over the other is sustained.

Just as the meaning of a word partly depends on what the word is not, the meaning of a text partly depends on what the text does not say. Deconstructive readings thus rely on gaps, inconsistencies, and contradictions in the text, and even on metaphorical associations. Deconstruction can serve as a tool for probing what psychology has represented as oppositions, such as autonomy-nurturance, instrumentality-expressiveness, mental health-mental illness. Our intention here is not to provide a detailed explication of deconstruction but to suggest some ways that it can be used to understand meaning and gender. Our focus here is on psychotherapy.

\section{Therapy, Meaning, and Change}

Therapy centers on meaning, and language is its medium. Therapy is an oral mode, and narratives, proverbs, metaphors, and interpretations are its substance. The metaphorical language used in therapy to represent the world is a way to try 
to comprehend partially what cannot be comprehended totally (Spence, 1987). A deconstructivist view of the process of therapy draws attention to the play of meanings in the therapist-client dialogue and the way a therapist poses alternative meanings to create possibilities for change. This renegotiation of the client's meanings can take place explicitly, as in psychodynamic therapies, cognitive therapy, or rational-emotive therapy. Or it can take place implicitly, as when a behavior therapist instructs a client on how to bring anxiety symptoms under voluntary control, or a pharmacotherapist reattributes symptoms of depression to disturbances in body chemistry. The therapeutic process can be seen as one in which the client asks the therapist to reveal something about the client beyond the client's awareness, something that the client does not know.

Clients in therapy talk not about actual experiences but about reconstructed memories that resemble the original experiences only in certain ways. The client's story conforms to prevailing narrative conventions (Spence, 1982). This means that the client's representation of events moves further and further away from the experience and into a descriptive mode. The client as narrator is a creator of his or her world, not a disinterested observer.

The therapist's task of listening and responding to the client's narratives is akin to a deconstructive reading of a text. Both seek subtexts and multiple levels of meaning. Just as deconstructive readings disrupt the frame of reference that organizes conventional meanings of a text, so a therapist's interventions disrupt the frame of reference within which the client customarily sees the world. Such disruptions enable new meanings to emerge (Watzlawick, Weakland \& Fisch, 1974). As a multiplicity of meanings becomes apparent through such therapist actions as questioning, explaining, interpreting, and disregarding, more possibilities for change emerge. The deconstructive process is most apparent in psychoanalysis, but, indeed, all therapy involves changing meaning as part of changing behavior. The metaphor of therapy as healing is an idealization that obscures another metaphor, that therapists manipulate meanings. These metaphors are not contrary to each other; rather, as part of helping clients change, therapists change clients' meanings (Frank, 1976; Haley, 1987).

\section{Gender and Meaning in Therapy}

Just as a poem can have many readings, a client's experience can have many meanings. Certain meanings are privileged, however, because they conform to the explanatory systems of the dominant culture. As a cultural institution whose purpose is to help individuals adapt to their social condition, therapy usually reflects and promulgates such privileged meanings. But some therapists, such as radical therapists and feminist therapists, bring a social critique to their work. Such therapists, rather than attempting to bring clients' meanings in line with those of the culture, disrupt the meanings privileged by the culture. Below, we examine certain privileged and marginalized meanings in relation to gender issues, issues that have been at the center of considerable debate among therapists and in society at large (Brodsky \& Hare-Mustin, 1980). 
We begin with Freud's classic case of Dora (1963). When we look at Dora's case from a deconstructive perspective, we can see it as a therapist's attempt to adjust the meaning a client attached to her experience to match the prevailing meanings of the patriarchal society in which she lived. A "landmark of persuasion unsurpassed in clinical literature" is the way Spence described Dora's case $(1987,122)$. Dora viewed the sexual attentions of her father's associate, Herr $K$, as unwanted and uninvited. She responded to them with revulsion. Freud insistently reframed the sexual encounters with Herr $\mathrm{K}$ as desired and desirable for a fourteen-year-old girl and interpreted Dora's revulsion as a disguise for her true state of sexual arousal. When Dora refused to accept Freud's construction, he labeled her as vengeful and declared therapy a failure.

From our vantage point ninety years after Dora's encounter with Freud, the case shows how meanings embedded in the dominant culture often go unrecognized or unacknowledged. Freud evidently viewed Herr K's lecherous advances as acceptable behavior, although Herr $\mathrm{K}$ was married and Dora was only fourteen and the daughter of a close family friend. We can surmise that the cultural belief in the primacy of men's sexual needs prevented Freud from seeing Dora's revulsion as genuine.

Freud's analysis of Dora provides an example of how a therapist attempts to reaffirm privileged meanings and marginalize and discourage other meanings, to fill in the gaps and make intelligible a narrative. Where does Dora leave off and Freud begin? The many meanings of Dora's behavior-and Freud's as well-are evident in the numerous reanalyses, filmic representations, and critical literary readings of the case, which continue to be produced up to the present day.

Conventional meanings of gender are embedded in the language of therapy. Like all language, the language used in therapy can be thought of as metaphoric: it selects, emphasizes, suppresses, and organizes certain features of experience, and thus it imparts meaning to experience; for example, Oedipus complex imposes the complexity of adult erotic feelings onto the experiences of small children and emphasizes the male and the primacy of the phallus. The metaphor of the family ledger in family therapy implies that family relations are (or should be) organized as mercantile exchanges and centered on male achievements (Boszormenyi-Nagy \& Sparks, 1973).

Dominant meanings are often embedded in everyday language and commonplace metaphors. By challenging linguistic conventions and unpacking metaphors, therapists can disrupt these meanings. With respect to gender, for example, a therapist can unpack the metaphor of family harmony and expose the gender hierarchy by pointing out that accord within the family often is maintained by women's acquiescence and accommodation (Haavind, 1984; HareMustin, 1978; 1987). Moreover, the stress generated by women's prescribed family roles is often marginalized or overlooked (Baruch, Biener \& Barnett, 1987). Psychologists studying stress have focused largely on men with men's workplace identified as a stressor. The home, in contrast, has been viewed as a benign envi- 
ronment in which one recuperates from work. This picture is drawn from a male perspective. For most women, the home is the workplace or at least one of their workplaces. Further, women's roles associated with the home are not free of undue stress. Family harmony involves a woman's pleasing a husband and keeping a home attractive, activities that are frequently incompatible with meeting children's needs (Piotrkowski \& Repetti, 1984).

In unpacking the metaphor of family loyalty, the therapist can draw attention to the way the needs of some family members are subordinated to those of dominant members in the name of loyalty. In maintaining the ties in the family network, women provide for others while their own needs go unmet (Belle, 1982).

The metaphor of women's dependency can also serve to conceal the extent to which women as wives and mothers provide for the needs of men and boys. Women have traditionally been characterized as dependent, but Harriet Lerner (1983) raises the provocative questions: Have women been dependent enough? Have they been able to call on others to meet their needs? As Westkott (1986) observes, the assumption of male entitlement to unconditional nurturance from females is rarely questioned; nor is it labeled as dependency and regarded as a psychological problem.

Finally, both private concerns with preserving the family and public rhetoric about the decline of the family can be challenged by drawing attention to the use of "the family" as a metaphor for male dominance (Pogrebin, 1983). Is it the family that is threatened or just a form of the family that supports men's greater power and status? Judith Stacey (1983) also draws attention to the way feminist theory has deconstructed the family as a natural unit and reconstructed it as a social unit.

As we have shown, the resemblance of therapeutic discourse to narrative offers the possibility of using deconstruction as a resource for understanding meaning and the process of therapy. Therapy typically confirms privileged meanings, but deconstruction directs attention to marginalized meanings. Doing therapy from a feminist standpoint is like the deconstructionist's "reading as a woman" (Culler, 1982). The therapist exposes gender-related meanings that reside in such culturally embedded metaphors as family harmony but go unacknowledged in the conventional understanding of those metaphors. These new meanings can change the ways that clients understand their own behaviors and the behaviors of othersthe click experience that women in the consciousness-raising groups of the $1960 \mathrm{~s}$ and $1970 s$ so often reported. New meanings allow and often impel clients to make changes in their lives.

\section{Paradoxes in Gender Theorizing}

The issue of gender differences has been a divisive one for feminist scholars. Some believe that affirming difference affirms women's value and special nature. Others believe that insisting on equality (that is, no difference) is necessary for social 
change and the redistribution of power and privilege. But both ways of representing gender involve paradoxes. Like every representation, both conceal as they reveal. A paradox is contrary (para) to received opinion (doxa), a logical impossibility or a result contrary to what is desired.

One such paradox is that efforts to affirm the special value of women's experience and to valorize women's inner life turn attention away from efforts to change the material conditions of women's lives (Fine, 1985; Russ, 1986; Tobias, 1986). Feelings of emotional intensity may not lead to an understanding of oneself or of society. A change in consciousness and symbolic life alone does not necessarily produce a change in the social conditions of individuals' lives and institutional structures.

Another paradox arises from the assertion of a female way of knowing, involving intuition and experiential understanding rather than logical abstraction. This assertion implies that all other ways of knowing are male. If taken to an extreme, the privileging of emotion and bodily knowledge over reason can lead to the rejection of rational thought. It can also be taken to imply that women are incapable of rational thought and of acquiring the knowledge of the dominant culture.

There is yet another paradox. Qualities such as caring, expressiveness, and concern for relationships are extolled as women's superior virtues and the wellspring of public regeneration and morality. But they are also seen as arising from women's subordination (Miller, 1976) and from women's being outsiders and oppressed. Thus has Bertrand Russell spoken of the superior virtue of the oppressed. When we extol such qualities as women's caring, do we necessarily also extol women's subordination (Echols, 1983)? Joan Ringleheim (1985) has suggested that the idealization of women's experience serves as a palliative for oppression. If subordination makes women better people, then the perpetuation of women's socalled goodness would seem to require continued subordination.

It is not only alpha bias that leads to paradoxes and logical confusion. Beta bias also can. Saying that women are as good as men is a statement of self-acceptance and pride for some women. But asserting that women are equal to men is not the same as asserting that women and men are equal; it reveals that man is the hidden referent in our language and culture. As Dale Spender (1984) points out, "women can only aspire to be as good as a man, there is no point in trying to be as good as a woman" (201). Paradoxically, this attempt at denying differences reaffirms male behavior as the standard against which all behavior is judged.

There is a paradox faced by any social change movement, including feminism: its critique is necessarily determined by the nature of the prevailing social system, and its meanings are embedded in that system. Sennett (1980) has observed a further paradox, that even when one's response to authority is defiance, that stance serves to confirm authority just as compliance does. Thus, the feminist critique simultaneously protests and protects the status quo. In this regard, Dorothy Dinnerstein (1976) has suggested that woman is not really the enemy of the system but its loyal opposition.

Moreover, feminist separatism, the attempt to avoid male influence by separating from men, leaves intact the larger system of male control in the society. Sepa- 
ratism can provide space for self-affection and woman-to-woman bonding, but as an ultimate goal it is caught as a mirror image of the masculine reality it is trying to escape (Cornell \& Thurschwell, 1987).

The meaning of gender as male-female difference presents us with paradoxes. Whether such representations of gender emphasize difference or minimize it, they are fraught with logical contradictions and hidden meanings. The representation of gender as male-female difference obscures and marginalizes the interrelatedness and commonalities of women and men. It also obscures institutional sexism and the extent of male authority. Just as our examination of the utility of alpha bias and beta bias revealed no clear answer for those who ask the question of which is better, so too the paradoxes that arise reveal further complexities and contradictions. Can we look beyond these representations to new ways of understanding gender?

\section{Conclusion}

Male-female difference is a problematic and paradoxical way to construe gender. What we see is that alpha and beta bias have similar assumptive frameworks despite their diverse emphases. Both take the male as the standard of comparison. Both construct gender as attributes of individuals, not as the ongoing relations of men and women. Neither effectively challenges the gender hierarchy, and ultimately neither transcends the status quo. They are changes within the larger system of assumptions, but they leave the system itself unchanged. The multiple representations all frame the problem of what gender is in such a way that the solution is "more of the same" (Watzlawick, Weakland \& Fisch, 1974).

Gender is not a property of individuals but a socially prescribed relationship, a process, and a social construction. Like race and class, however, gender cannot be renounced voluntarily. Representing gender as a continuum of psychological difference serves to simplify and purify the concept of gender. The riddle of gender is presumed to be solved when heterogeneous material is reduced to the homogeneity of logical thought (Gallop, 1982). To establish a dichotomy is to avoid complexity. The idea of gender as opposites obscures the complexity of human action and shields both men and women from the discomforting recognition of inequality.

The issue of difference is salient for men in a way that it is not for women. Those who are dominant have an interest in emphasizing those differences that reaffirm their superiority and in denying their similarity to subordinate groups. By representing nonsymmetrical relationships as symmetrical, those who are dominant obscure the unequal social arrangements that perpetuate male dominance. Thus, notions of gender that are part of our cultural heritage rely on defensive masculine models of gender (Chodorow, 1979). In accepting male-female difference as the meaning of gender, feminists have acceded to the construction of reality of the dominant group, "a gentle slide into the prevailing hegemony" (Bouchier, 1979, 397). 
Even when differences are minimized and gender is represented as male-female similarity, equality remains elusive. Male themes and male views are presented as human experience. As Sandra Harding (1986) has observed, women are asked to degender themselves for a masculine version of experience without asking for a similar degendering of men. Even women's need to define themselves derives from and is perpetuated by their being the nondominant group. The dominant group does not define itself with respect to its group or order. Thus men do not refer to their masculine status, they do not add "as a man." But women speak "as a woman." Specifying "as a woman" reserves generality for men.

Deconstruction focuses attention on oppositions and hidden meanings in language. Language mirrors social relations, but it is also recursive on the social experiences that generate it. Thus, from a postmodernist perspective, there is no one right view of gender. Each view is partial and will present certain paradoxes. Feminist psychology has concentrated on male-female difference. Though the remapping of difference could go further, such a map of difference, even if perfected, will never reveal the entire terrain of gender. A map is not the terrain. Rather a map offers a construction of the terrain. With regard to gender, there are other maps to be drawn. For instance, some would map gender in terms of the principles that organize male-female relations in particular cultures (Stacey \& Thorne, 1985). Some would map gender in terms of the discourses through which men and women position one another and define themselves (Hollway, 1984). Other maps, charting gender in yet other terms, are still be be invented.

Postmodernism accepts multiplicity, randomness, incoherence, indeterminacy, and paradox, which positivist paradigms are designed to exclude. Postmodernism creates distance from the seemingly fixed language of established meanings and fosters skepticism about the fixed nature of reality. Recognizing that meaning is what we agree on, postmodernism describes a system of possibilities. Constructing gender is a process, not an answer. In using a postmodernist approach, we open the possibility of theorizing gender in heretofore unimagined ways. Postmodernism allows us to see that as observers of gender we are also its creators.

\section{References}

Andersen, M. L. (1983). Thinking about women: Sociological and feminist perspectives. New York: Macmillan.

Bakan, D. (1966). The duality of human existence. Chicago: Rand McNally.

Barthes, R. (1972). Mythologies (A. Lavers, Trans.). New York: Hill \& Wang. (Original work published 1957.)

Baruch, G. K., Biener, L., \& Barnett, R. C. (1987). Woman and gender in research on work and family stress. American Psychologist, 42, 130-36.

Beauvoir, S. de. (1953). The second sex (H. M. Parshley, Trans. \& Ed.). New York: Knopf.

Belenky, M. F., Clinchy, B. M., Goldberger, N. R. \& Tarule, J. M. (1986). Women's ways of knowing: Development of self, voice, and mind. New York: Basic Books.

Belle, D. (1982). Social ties and social support. In D. Belle (Ed.), Lives in stress: Women and depression (133-44). Beverly Hills: Sage. 
Bem, S. L. (1976). Probing the promise of androgyny. In A. G. Kaplan \& J. P. Bean (Eds.), Beyond sex-role stereotypes: Reading toward a psychology of androgyny (48-62). Boston: Little, Brown.

Bernal, G. \& Ysern, E. (1986). Family therapy and ideology. Journal of Marital and Family Therapy. 12, 129-35.

Bloom, A. H. (1981). The linguistic shaping of thought. Hillsdale, NJ: Erlbaum.

Boszormenyi-Nagy, I. \& Sparks, G. M. (1973). Invisible loyalties. New York: Harper \& Row.

Bouchier, D. (1979). The deradicalisation of feminism: Ideology and utopia. Sociology, 13, $387-402$.

Brodsky, A. M., \& Hare-Mustin, R. T. (1980). Women and psychotherapy: An assessment of research and practice. New York: Guilford.

Bronfenbrenner, U., Kessel, F., Kessen, W. \& White, S. (1986). Toward a critical social history of developmental psychology: A propaedeutic discussion. American Psychologist, 41, 1218-30.

Broverman, I. K., Broverman, D. M., Clarkson, F. E., Rosenkrantz, P. \& Vogel, S. R. (1970). Sex role stereotypes and clinical judgments of mental health. Journal of Consulting Psychology, 34, 1-7.

Bruner, J. (1986). Actual minds, possible worlds. Cambridge, MA: Harvard University Press.

Butler, J. (1987). Variations on sex and gender. In S. Benhabib \& D. Cornell (Eds.), Feminism as critique: On the politics of gender (128-42). Minneapolis: University of Minnesota Press.

Chernin, K. (1986). The hungry self: Women, eating, and identity. New York: Perennial Library.

Chodorow, N. (1978). The reproduction of mothering. Berkeley: University of California Press.

Chodorow, N. (1979). Feminism and difference: Gender, relation, and difference in psychoanalytic perspective. Socialist Review, 9 (4), 51-70.

Constantinople, A. (1973). Masculinity-femininity: An exception to a famous dictum? Psychological Bulletin, 80, 389-407.

Cornell, D. \& Thurschwell, A. (1987). Feminism, negativity, intersubjectivity. In S. Benhabib \& D. Cornell (Eds.), Feminism as critique: On the politics of gender (143-62). Minneapolis: University of Minnesota Press.

Cowan, R. S. (1983). More work for mother: The ironies of household technology from open hearth to microwave. New York: Basic Books.

Culler, J. (1982). On deconstruction: Theory and criticism after structuralism. Ithaca, NY: Cornell University Press.

Deaux, K. (1984). From individual differences to social categories: Analysis of a decade's research on gender. American Psychologist, 39, 105-16.

Dell, P. F. (1985). Understanding Bateson and Maturana: Toward a biological foundation for the social sciences. Journal of Marital and Family Therapy, 11, 1-20.

Dinnerstein, D. (1976). The mermaid and the minotaur. New York: Harper \& Row.

Dionne, E. J. (1989, August 22). Struggle for work and family fueling women's movement. New York Times, A1, A18.

Eagleton, T. (1983). Literary theory: An introduction. Minneapolis: University of Minnesota Press.

Eagly, A. H. \& Crowley, M. (1986). Gender and helping behavior: A meta-analytic review of the social psychological literature. Psychological Bulletin, 100, 283-308.

Eagly, A. H. \& Steffen, V. J. (1986). Gender and aggressive behavior: A meta-analytic review of the social psychological literature. Psychological Bulletin, 100, 309-30. 
Eccles, J. S. (1989). Bringing young women to math and science. In M. Crawford \& M. Gentry (Eds.) Gender and thought (36-58). New York: Springer-Verlag.

Eccles, J. \& Jacobs, J. (1986). Social forces shape math participation. Signs, 11, 368-80.

Echols, A. (1983). The new feminism of yin and yang. In A. Snitow, C. Stansell \& S. Thompson (Eds.), Powers of desire: The politics of sexuality (440-59). New York: Monthly Review Press.

Eichenbaum, L. \& Orbach, S. (1983). Understanding women: A feminist psychoanalytic approach. New York: Basic Books.

Eisenstein, H. (1983). Contemporary feminist thought. Boston: G. K. Hall.

Erikson, E. H. (1964). Inner and outer space: Reflections on womanhood. Daedelus, 93, $582-$ 606.

Fine, M. (1985). Reflections on a feminist psychology of women. Psychology of Women Quarterly, 9, 167-83.

Flax, J. (1987). Postmodernism and gender relations in feminist theory. Signs, 12, 621-43.

Foucault, M. (1973). The order of things. New York: Vintage.

Frank, J. D. (1987). Psychotherapy, rhetoric, and hermeneutics: Implications for practice and research. Psychotherapy, 24, 293-302.

Freud, S. (1963). Dora: An analysis of a case of hysteria. New York: Collier Books. (Original work published 1905.)

Freud, S. (1964). Some psychical consequences of the anatomical distinction between the sexes. In J. Strachey (Ed. and Trans.), Standard edition of the complete psychological works of Sigmund Freud (Vol. 19, 243-58). London: Hogarth Press. (Original work published 1925.)

Gallop, J. (1982). The daughter's seduction: Feminism and psychoanalysis. Ithaca, NY: Cornell University Press.

Gergen, K. J. (1985). The social constructionist movement in modern psychology. American Psychologist, 40, 266-75.

Gervasio, A. H. \& Crawford, M. (1989). The social evaluation of assertion: A critique and speech act reformulation. Psychology of Women Quarterly, 13, 1-25.

Gilbert, L. A. (1980). Feminist therapy. In A. M. Brodsky \& R. T. Hare-Mustin (Eds.), Women and psychotherapy: An assessment of research and practice (245-65). New York: Guilford.

Gilder, G. (1987). Men and marriage. Los Angeles: Pelican.

Gilligan, C. (1982). In a different voice: Psychological theory and women's development. Cambridge: Harvard University Press.

Goldner, V. (1987). Instrumentalism, feminism, and the limit of family therapy. Journal of Family Psychology, 1, 109-16.

Gough, H. G. (1964). California psychological inventory: Manual. Palo Alto: Consulting Psychologists Press.

Grimshaw, J. (1986). Philosophy and feminist thinking. Minneapolis: University of Minnesota Press.

Haavind, H. (1984). Love and power in marriage. In H. Holter (Ed.), Patriarchy in a welfare society (136-67). Oslo: Universitets Forlaget. Distribution in U.S.: New York: Columbia University Press.

Haley, J. (1976). Problem-solving therapy. San Francisco: Jossey-Bass.

Harding, S. (1986). The science question in feminism. Ithaca, NY: Cornell University Press.

Hare-Mustin, R. T. (1978). A feminist approach to family therapy. Family Process, 17, 181-94.

Hare-Mustin, R. T. (1983). An appraisal of the relationship of women and psychotherapy: 80 years after the case of Dora. American Psychologist, 1983, 38, 593-601. 
Hare-Mustin, R. T. (1987). The problem of gender in family therapy theory. Family Process, 26, 15-27.

Hare-Mustin, R. T. (1988). Family change and gender differences: Implications for theory and practice. Family Relations, 37, 36-41.

Hare-Mustin, R. T. \& Marecek, J. (1986). Autonomy and gender: Some questions for therapists. Psychotherapy, 23, 205-12.

Hartsock, N. C. M. (1985). Money, sex, and power: Toward a feminist historical materialism. Boston: Northeastern University Press.

Hathaway, S. R. \& McKinley, J. C. (1943). The Minnesota Multiphasic Personality Test. New York: Psychological Corporation.

Heisenberg, W. (1952). Philosophical problems of nuclear science (F. C. Hayes, Trans.). New York: Pantheon.

Hollway, W. (1984). Gender difference and the production of subjectivity. In J. Henriques, W. Hollway, C. Urwin, C. Venn \& V. Walkerdine (Eds.), Changing the subject (26-59). London: Methuen.

Howard, G. (1985). The role of values in the science of psychology. American Psychologist, $40,255-65$.

Hyde, J. S. (1981). How large are cognitive gender differences? American Psychologist, 36, 892-901.

Jacobson, N. S. (1983). Beyond empiricism: The politics of marital therapy. American Journal of Family Therapy, 11 (2), 11-24.

Jameson, F. (1981). The political unconscious: Narrative as a socially symbolic act. Ithaca, NY: Cornell University Press.

Jordan, J. V. \& Surrey, J. L. (1986). The self-in-relation: Empathy and the mother-daughter relationship. In T. Bernay \& D. W. Cantor (Eds.), The psychology of today's woman: New Psychoanalytic visions (81-104). New York: The Analytic Press.

Kagan, J. (1984). The nature of the child. New York: Basic Books.

Keller, E. F. (1985). Reflections on gender and science. New Haven: Yale University Press.

Kessler, S. J. \& McKenna, W. (1978). Gender: An ethnomethodological approach. Chicago: University of Chicago Press.

Kuhn, T. S. (1962). The structure of scientific revolutions. Chicago, IL: University of Chicago Press.

Lacan, J. (1985). Feminine sexuality (J. Mitchell \& J. Rose, Eds.; J. Rose, Trans.). New York: Norton.

Lasch, C. (1977). Haven in a heartless world. New York: Basic Books.

Lerner, H. G. (1983). Female dependency in context: Some theoretical and technical considerations. American Journal of Orthopsychiatry, 53, 697-705.

Libow, J. (1985). Gender and sex role issues as family secrets. Journal of Strategic and Systemic Therapies, 4, (2), 32-41.

Lipman-Blumen, J. (1984). Gender roles and power. Englewood Cliffs, NJ: Prentice-Hall.

Lott, B. (1985). The potential enrichment of social/personality psychology through feminist research and vice versa. American Psychologist, 40, 155-64.

Lott, B. (1987). Women's lives: Themes and variations. Belmont, CA: Brooks/Cole.

Luria, Z. (1986). A methodological critique: On "In a different voice" Signs, 11, 316-21.

Maccoby, E. E. \& Jacklin, C. N. (1975). The psychology of sex differences. Stanford, CA: Stanford University Press.

MacKinnon, L. K. \& Miller, D. (1987). The new epistemology and the Milan approach: Feminist and sociopolitical considerations. Journal of Marital and Family Therapy, 13, 139-55. 
Marecek, J. \& Hare-Mustin, R. T. (1987, March). Cultural and radical feminism in therapy: Divergent views of change. Paper presented at the meeting of the American Orthopsychiatric Association, Washington, DC.

Marecek, J. \& Kravetz, D. (1977). Women and mental health: A review of feminist change efforts. Psychiatry, 40, 323-29.

Margolin, G., Talovic, S., Fernandez, V. \& Onorato, R. (1983). Sex role considerations and behavioral marital therapy: Equal does not mean identical. Journal of Marital and Family Therapy, 9, 131-45.

Marshner, C. (1982). The new traditional woman. Washington, DC: Fress Congress Education and Research Foundation.

Mednick, M. T. (1989). On the politics of psychological constructs: Stop the bandwagon, I want to get off. American Psychologist, 44, 1118-23.

Merchant, C. (1980). The death of nature: Women, ecology, and the scientific revolution. San Francisco: Harper \& Row.

Miller, J. B. (1986). Toward a new psychology of women (2d ed.). Boston: Beacon Press.

Mills, P. J. (1987). Woman, nature, and psyche. New Haven: Yale University Press.

Minuchin, S. (1974). Families and family therapy. Cambridge: Harvard University Press.

Morawski, J. G. (1985). The measurement of masculinity and femininity: Engendering categorical realities. Journal of Personality, 53, 196-223.

Morawski, J. G. (1987). The troubled quest for masculinity, femininity, and androgyny. In P. Shaver \& C. Hendrick (Eds.), Review of Social and Personality Psychology: Vol. 7. Sex and gender (44-69). Beverly Hills: Sage.

Muehlenhard, C. L. (1983). Women's assertion and the feminine sex-role stereotype. In V. Frank \& E. D. Rothblum (Eds.), The stereotyping of women: Its effects on mental health $(153-71)$. New York: Springer.

Nehamas, A. (1987, 5 October). Truth and consequences: How to understand Jacques Derrida. The New Republic, pp. 31-36.

Newland, K. (1979). The sisterhood of man. New York: Norton.

Nye, F. I. (1982). Family relationships: Rewards and costs. Beverly Hills: Sage.

Ortner, S. B. (1974). Is female to male as nature is to culture? In M. Z. Rosaldo \& L. Lamphere (Eds.), Women, culture, and society $(67-87)$. Stanford: Stanford University Press.

Park, B., \& Rothbart, M. (1982). Perception of out-group homogeneity and levels of social categorization: Memory for the subordinate attributes of in-group and out-group members. Journal of Personality and Social Psychology, 42, 1051-68.

Parsons, T. \& Bales, R. F. (1955). Family, socialization, and interaction process. Glencoe, IL: Free Press.

Piotrkowski, C. S. \& Repetti, R. L. (1984). Dual-earner families. In B. B. Hess \& M. B. Sussman (Eds.), Women and the family: Two decades of change (99-124). New York: Haworth Press..

Pogrebin, L. C. (1983). Family politics: Love and power on an intimate frontier. New York: McGraw-Hill.

Ringleheim, J. (1985). Women and the Holocaust: A reconsideration of research. Signs, 10, 741-61.

Rorty, R. (1979). Philosophy and the mirror of nature. Princeton: Princeton University Press. Rosenberg, R. (1986). Offer of proof concerning the testimony of Dr. Rosalind Rosenberg (EEOC v. Sears, Roebuck, and Company), Signs, 11, 757-66.

Rossi, A. (1984). Gender and parenthood. American Sociological Review, 49, 1-19.

Russ, J. (1986). Letter to the editor. Women's Review of Books, 3 (12), 7. 
Sampson, E. E. (1985). The decentralization of identity: Toward a revised concept of personal and social order. American psychologist, 40, 1203-11.

Scarr, S. (1985). Constructing psychology: Making facts and fables for our times. American Psychologist, 40, 499-512.

Schlachet, B. C. (1984). Female role socialization: The analyst and the analysis. In C. M. Brody (Ed.), Women therapists for working with women (55-65). New York: Springer.

Scott, J. W. (1985, December). Is gender a useful category of historical analysis? Paper presented at the meeting of the American Historical Association, New York.

Segal, L. (1986). The dream of reality: Heinz von Foerster's constructivism. New York: Norton. Sennett, R. (1980). Authority. New York: Knopf.

Shields, S. A. (1975). Functionalism, Darwinism, and the psychology of women. A study in social myth. American Psychologist, 30, 739-54.

Spence, D. P. (1982). Narrative truth and historical truth. New York: Norton.

Spence, D. P. (1987). The Freudian metaphor: Toward a paradigm change in psychoanalysis. New York: Norton.

Spender, D. (1984). Defining reality: A powerful tool. In C. Kramarae, M. Schulz \& W. M. O'Barr (Eds.), Language and power (194-205). Beverly Hills: Sage.

Stacey, J. (1983). The new conservative feminism. Feminist Studies, 9, 559-83.

Stacey, J. \& Thorne, B. (1985). The missing feminist revolution in sociology. Social Problems, 32, 301-16.

Strainchamps, E. (Ed.). (1974). Rooms with no view: A woman's guide to the man's world of the media. New York: Harper \& Row.

Taggart, M. (1985). The feminist critique in epistemological perspective: Questions of context in family therapy. Journal of Marital and Family Therapy, 11, 113-26.

Terman, L. \& Miles, C. C. (1936). Sex and personality. New York: McGraw-Hill.

Thorne, B. (1982). Feminist rethinking of the family: An overview. In B. Thorne \& M. Yalom (Eds.), Rethinking the family: Some feminist questions (1-24). New York: Longmans.

Tiefer, L. (1987). Social constructionism and the study of human sexuality. In P. Shaver \& C. Hendrick (Eds.), Review of Social and Personality Psychology: Vol. 7. Sex and gender (7094). Beverly Hills: Sage.

Tobias, S. (1986). "In a different voice" and its implications for feminism. Women's Studies in Indiana, 12, (2), 1-2, 4.

Unger, R. K. (1979). Toward a redefinition of sex and gender. American Psychologist, 34, 1085-94.

Unger, R. K. (1983). Through the looking glass: No wonderland yet! (The reciprocal relationship between methodology and models of reality). Psychology of Women Quarterly, 8, 9-32.

Von Glaserfeld, E. (1984). An introduction to radical constructivism. In P. Watzlawick (Ed.), The invented reality: Contributions to constructivism (17-40). New York: Norton.

Wallston, B. S. (1981). What are the questions in psychology of women? A feminist approach to research. Psychology of Women Quarterly, 5, 597-617.

Watzlawick, P. (Ed.) (1984). The invented reality: Contributions to constructivism. New York: Norton.

Watzlawick, P., Weakland, J. H. \& Fisch, R. (1974). Change: Principles of problem formation and problem resolution. New York: Norton.

Weisstein, N. (1971). Psychology constructs the female. In V. Gornick \& B. K. Moran (Eds.), Woman in sexist society (133-46). New York: Basic Books.

Weitzman, L. J. (1985). The divorce revolution: The unexpected social and economic consequences for women and children in America. New York: Free Press. 
Westkott, M. (1986). Historical and developmental roots of female dependency. Psychotherapy, 23, 213-20.

Wilden, A. (1972). System and structure: Essays in communication and exchange. London: Tavistock Publications.

Wittgenstein, L. (1960). Preliminary studies for the "Philosophical Investigations": The blue and brown books. Oxford: Blackwell.

Wittgenstein, L. (1967). Philosophical investigations. Oxford: Blackwell. (Original work published 1953.)

Worell, J. (1978). Sex roles and psychological well-being: Perspectives on methodology. Journal of Consulting and Clinical Psychology, 46, 777-91.

Worell, J. (1988). Women's satisfaction in close relationships. Clinical Psychology Review, 8, 477-98.

Young, I. M. (1983). Is male gender identity the cause of male domination? In J. Trebilcot (Ed.), Mothering: Essays in feminist theory (129-46). Totowa, NJ: Rowman \& Allenheld. 